\title{
Effect of Perillyl Alcohol (POH) A Monoterpene on Lipid Peroxidation and Antioxidant Status in High Fat Diet-Low Dose STZ Induced Type 2 Diabetes in Experimental Rats
}

\author{
Towseef Hassan, Elanchezhiyan C*, Insha Naseer, S. Marimuthu
}

Towseef Hassan, Elanchezhiyan $C^{*}$, Insha Naseer, S. Marimuthu

Department of Zoology, Annamalai

University, Annamalainagar

Chidambaram-608002, Tamil Nadu, INDIA

\section{Correspondence}

\section{Dr. C. Elanchezhiyan}

Department of Zoology, Annamala University, Annamalainagar, Chidambaram-608002, Tamil Nadu, INDIA.

Phone No: +919865815558

E-mail: chezhiyan6@gmail.com

History

- Submission Date: 31-08-2019;

- Review completed: 04-10-2019;

- Accepted Date: 07-10-2019.

DOI : 10.5530/pj.2019.11.222

Article Available online

http://www.phcogj.com/v11/i6s

\section{Copyright}

(C) 2019 Phcogi.Com. This is an openaccess article distributed under the terms of the Creative Commons Attribution 4.0 International license.

\begin{abstract}
Aim: The plan of this study was to assess the protective activity of Perillyl alcohol $(\mathrm{POH})$ on the levels of lipid peroxidation (LPO) by-products and antioxidant defense systems in the plasma and other tissues of normal and High Fat Diet-Low Dose Streptozotocin (STZ) induced type 2 diabetes in wistar rats. Materials and Methods: The experimental diabetes was induced in animals by High Fat Diet-Low Dose STZ $(35 \mathrm{mg} / \mathrm{kg}$ i.p.) injection, and treatment with Perillyl alcohol at the dose of $(50 \mathrm{mg} / \mathrm{kg} \mathrm{b.w}$ and $100 \mathrm{mg} / \mathrm{kg} \mathrm{b.w})$ was continued for 30 days. At the end of treatment period, oxidative stress parameters like lipid peroxidation by-products; enzymatic antioxidants such as superoxide dismutase (SOD), catalase (CAT), glutathione peroxidase (GPx) and non-enzymic antioxidants including reduced glutathione, Vitamin $\mathrm{C}$ and Vitamin $\mathrm{E}$ were measured in the plasma and tissues of experimental rats. Results: In untreated diabetic rats an increase was seen in the levels of lipid peroxidation by-products and significant decrease was seen in antioxidant enzymes. Oral administration of Perillyl alcohol a monocyclic monoterpene to diabetic rats for 30 days caused a significant reduction in the levels of lipid peroxidation by-products and an increase in the activities of antioxidant enzymes, when the same were compared with the untreated diabetic group. Conclusion: The result of this study indicates that Perillyl alcohol has anti lipid peroxidation and antioxidant status potential in experimental diabetes.
\end{abstract}

Key words: High Fat Diet, Streptozotocin, Perillyl alcohol, Lipid Peroxidation, Antioxidants.

\section{INTRODUCTION}

Antioxidants are man-made or natural substances that bind to free radicals and thus prevent them from oxidative damage in normal healthy cells. Diabetes mellitus is said to be associated with increased oxidative stress, which could be a result of either increased production of free radicals or reduced antioxidant defenses in the body. ${ }^{1}$ High levels of ROS contribute to lipid peroxidation (LPO) in cellular membranes, increasing their fluidity and permeability. Specifically, high levels of Reactive Oxygen Species generate malondialdehyde (MDA), a highly toxic molecule in the body, and its secondary product, thiobarbituric acid reactive substances (TBARS), which is used as marker of LPO. $^{2}$

People with good health have a balance between free radicals and antioxidants in the body. However, it has been shown that people who have diabetes have higher levels of free radicals, which can cause diabetic complications. ${ }^{3}$ During diabetes, high glucose levels causes an increased production of free radicals in the different tissues of body, especially reactive oxygen species (ROS), from glucose autoxidation and protein glycosylation. ${ }^{4,5}$ Damage to cellular organelles and enzymes and an increase in lipid peroxidation can be caused by high levels of free radicals produced in body in diabetes condition and the simultaneous decline of antioxidant defense mechanisms. ${ }^{6,7}$

There are several other options to maintain normoglycemia in diabetic individuals, but most of the currently available antidiabetic medications elicit undesirable side effects and lessening in response after prolonged use. ${ }^{8}$ Plant-derived herbal remedies are apparently effective, produce very less or no side effects in clinical experience and are of relatively low costs as compared with oral synthetic hypoglycemic agents already available in market. ${ }^{9}$ Perillyl alcohol (POH) [Fig. 1] is a naturally occurring monocyclic monoterpene that can be purified from various plants such as peppermint, spearmint, cherries and celery. ${ }^{10}$ It has been shown by the researchers that $\mathrm{POH}$ possesses considerable anti-tumor, anticancer, anti-inflammatory and anti-fungal activity. ${ }^{11,12}$

The aim of this experiment is to find out the effect of $\mathrm{POH}$ on lipid peroxidation and oxidant status in varies tissues of High Fat Diet-Low Dose Streptozotocin (STZ) induced type 2 diabetes in wistar rats.

\section{MATERIALS AND METHODS}

\section{Animals}

Healthy male albino Wistar rats (160-180 g) were obtained from Biogen Laboratory Animal Facility, Bangalore India and maintained at a constant 
temperature $\left(25 \pm 1{ }^{\circ} \mathrm{C}\right)$ on a $12 \mathrm{~h}$ light $/ 12 \mathrm{~h}$ dark cycle with standard pellet diet (National Institute for Nutrition, Hyderabad, India) and water was provided ad libitum. The study was approved by the Institutional Animal Ethics Committee of Rajah Muthiah Medical College (Reg no. 160/PO/ReBi/S/1999/CPCSEA, Proposal no. 1192), Annamalai University.

\section{Chemicals}

Perillyl alcohol (POH) and Streptozotocin were purchased from SigmaAldrich (St. Louis, MO, USA) and other chemicals used in experiment were obtained from E. Merck, Himedia (Mumbai India). All of the chemicals and reagents used in these experiments were analytical grade (Figure 1).

\section{High fat diet- low dose streptozotocin induced diabetes}

The rats were divided into two dietary regimens by feeding either normal or high fat diet (HFD) for the initial period of four weeks. ${ }^{13}$ The ingredients and chemical composition of the HFD (Table 1) was followed as before reported. After four weeks of dietary manipulation, the groups of rats fed with HFD were injected intraperitoneal with a low dose of STZ ( $35 \mathrm{mg} / \mathrm{kg}$ b.w) dissolved in $0.1 \mathrm{M}$ cold citrate buffer, $\mathrm{pH}$ 4.5). Three days after STZ injection, the rats were screened for blood glucose level. Rats that are having fasting blood glucose (FBG) $>250 \mathrm{mg} / \mathrm{dl}$ that exhibited random hyperglycemia and glycosuria were selected for the experiment.

\section{Experimental design}

A total number of 30 rats were divided into 5 groups of six animals each (6 normal rats and 24 diabetic rats). Saline was used as vehicle. Perillyl alcohol and Glibenclamide were dissolved in saline and administered orally once in a day for 30 days.

Group 1- Normal rats treated with vehicle alone.

Group 2- HFD fed- STZ induced experimental diabetic rats. (35 mg/ $\mathrm{kg}$ bw).

Group 3- HFD fed- STZ induced diabetic rats orally treated with Perillyl alcohol (50 mg/kg b.w. / day for 30 days).

Group 4- HFD fed- STZ induced diabetic rats orally treated with Perillyl alcohol (100 mg/kg b.w /day for 30 days).

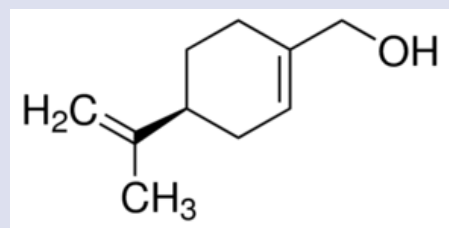

Figure 1: Structure of Perillyl alcoho $\left(\mathrm{C}_{10} \mathrm{H}_{16} \mathrm{O}\right)$.

Table 1: Composition of high fat diet.

\begin{tabular}{cc}
\hline Ingredients & Diet $(\mathrm{g} / 100 \mathrm{~g})$ \\
\hline Powdered NPD & 36.5 \\
Lard & 31 \\
Casein & 25 \\
Cholesterol & 1 \\
Sodium cholate & 0.5 \\
Vitamin mineral mix & 6 \\
dl-Methionine & 0.3 \\
Yeast powder & 0.1 \\
Sodium chloride & 0.1 \\
\hline
\end{tabular}

${ }^{*}$ The composition of normal pellet diet (NPD): $4.1 \%$ fat, $22.2 \%$ protein, and $12.1 \%$ carbohydrates, as a percentage of total kilocal.
Group 5- HFD fed- STZ induced diabetic rats orally treated with Glibenclamide ( $6 \mathrm{mg} / \mathrm{kg}$ b.w /day for 30 days).

During the experimental period, body weight, food and water consumption and physical examinations of rats were determined at regular intervals to check the changes occurring during experiment. At the end of the treatment period of 30 days the rats were fasted overnight and sacrificed by cervical decapitation in the morning.

\section{Sample collection}

Blood samples were collected from 12-hr fasted rats with capillary tube from retino-orbital plexus in fresh vials containing EDTA $(1.5 \mathrm{mg} / \mathrm{ml})$ as anticoagulant. The samples were centrifuged at $2500 \mathrm{RPM}$ for $10 \mathrm{~min}$ to obtain plasma.

\section{Estimation of biochemical parameters}

Plasma glucose was estimated colorimetrically by the method of Trinder using a reagent kit. ${ }^{14}$ Plasma insulin was measured by enzyme-linked immunosorbent assay (ELISA) according to the method of Berg et al. ${ }^{15}$ Thiobarbituric acid-reactive substances (TBARS) were measured in plasma and other tissues by the method of Niehaus and Samuelsson. ${ }^{16}$ Lipid hydroperoxides (LOOH) was estimated by using the method of Jiang et al. ${ }^{17}$. The activity of superoxide dismutase (SOD) was assayed by using the method of Kakkar et al. ${ }^{18}$ The activity of catalase (CAT) was determined by using the method of Sinha. ${ }^{19}$ The activity of Glutathione peroxidase (GPx) was estimated by the method of Rotruck et al. ${ }^{20}$ The activity of reduced GSH was determined by using the method of Ellman. ${ }^{21}$ Vitamin C was assessed by the method of Roe and Kuether ${ }^{22}$ a-tocopherol (Vitamin E) was estimated by the method of Baker et al. ${ }^{23}$ and expressed as $\mu \mathrm{g} / \mathrm{mg}$ of protein.

\section{STATISTICAL ANALYSIS}

All values are expressed as mean \pm SD for six rats in each group. Oneway ANOVA followed by Duncan's multiple range test (DMRT) using IBM SPSS version 22. Statistical significance was compared within the groups as follows: ${ }^{a}$ control rats; ${ }^{b}$ diabetic control rats. Values are statistically significant at ${ }^{\star} p<0.05$.

\section{RESULTS}

\section{Effect of Perillyl alcohol on blood glucose and plasma insulin}

Figures 2 and 3 depicts the level of plasma glucose and insulin in normal and diabetic rats. The diabetic rats showed increased glucose level and decreased plasma insulin level, whereas treatment with Perillyl alcohol and glibenclamide decreased the glucose level and increased the insulin level in the HFD-Low Dose STZ induced diabetes in rats.

\section{Effect of $\mathrm{POH}$ on lipid peroxidation}

Tables 2 and 3 represent TBARS and $\mathrm{LOOH}$ concentration in plasma and tissues (liver, kidney, and pancreas) of control and experimental rats. TBARS and LOOH levels were significantly $(p<0.05)$ elevated in diabetic control rats when compared with normal control rats, whereas diabetic rats treated with $\mathrm{POH} 50 \mathrm{mg}$ and $100 \mathrm{mg} / \mathrm{kg}$ body weight for 30 days orally significantly decrease the elevated levels of TBARS and LOOH when compared with diabetic control rats.

\section{Effect of $\mathrm{POH}$ on enzymatic antioxidant enzymes}

Tables 4-6 depicts the antioxidant enzymes levels such as SOD, CAT and GPx respectively were significantly lessen in diabetes induced rats when compared with normal control rats. $\mathrm{POH}$ treated diabetic rats for the period of 30days showed significant improvement in the levels of SOD, CAT and GPx in plasma and other body tissues (liver, kidney and pancreas) when the treated rats were compared to diabetic control rats. 


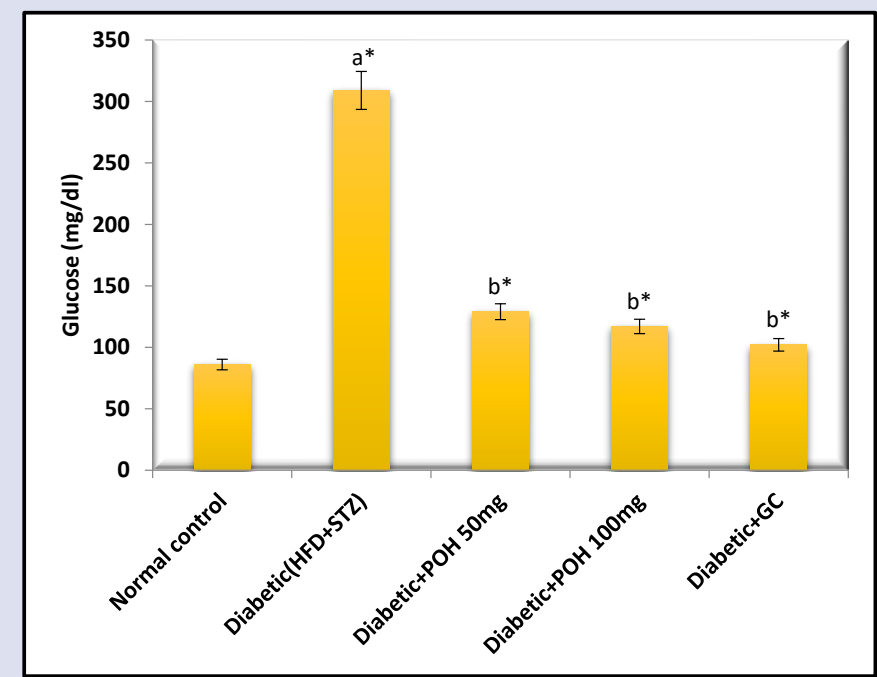

Figure 2: Effect of Perillyl alcohol (POH) on Blood Glucose in high fat diet-low dose STZ induced diabetes in experimental rats. All values are expressed as mean \pm SD for six rats in each group. One-way ANOVA followed by Duncan's multiple range test (DMRT). Statistical significance was compared within the groups as follows: ${ }^{a}$ control rats; ${ }^{b}$ diabetic control rats. Values are statistically significant at ${ }^{*} p<0.05$.

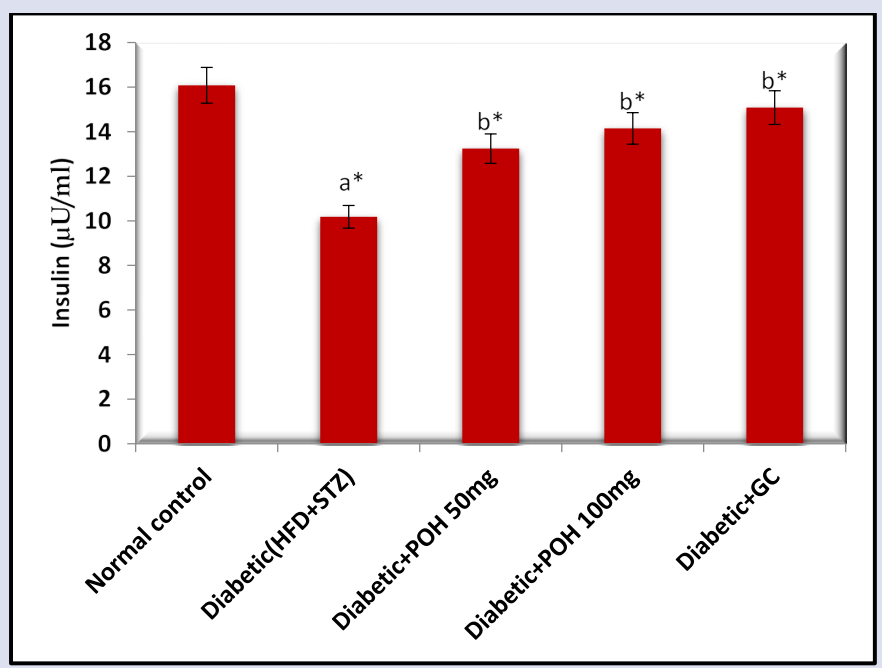

Figure 3: Effect of Perillyl alcohol (POH) on Plasma Insulin in high fat diet-low dose STZ induced type2 diabetes in experimental rats. All values are expressed as mean \pm SD for six rats in each group. One-way ANOVA followed by Duncan's multiple range test (DMRT). Statistical significance was compared within the groups as follows: ${ }^{\text {ccontrol rats; }}{ }^{b}$ diabetic control rats. Values are statistically significant at ${ }^{*} p<0.05$.

Table 2: Effect of Perillyl alcohol on Lipid peroxidation by product (TBARS) in plasma and different organs on High fat diet- low dose Streptozotocin induced diabetic rats.

\begin{tabular}{lcccc}
\hline \multicolumn{1}{c}{ Groups } & Plasma & Liver & Kidney & Pancreas \\
\hline Normal control & $0.19 \pm 0.02$ & $0.90 \pm 0.07$ & $1.44 \pm 0.11$ & $0.25 \pm 0.02$ \\
Diabetic (HFD+STZ) & $0.33 \pm 0.02^{\mathrm{a}^{*}}$ & $4.12 \pm 0.29^{\mathrm{a}^{*}}$ & $3.70 \pm 0.28^{\mathrm{a}^{*}}$ & $0.44 \pm 0.03^{\mathrm{a}^{*}}$ \\
Diabetic + POH (50mg/kg b w) & $0.27 \pm 0.03^{\mathrm{b}^{*}}$ & $2.05 \pm 0.15^{\mathrm{b}^{*}}$ & $2.77 \pm 0.13^{\mathrm{b}^{*}}$ & $0.41 \pm 0.05^{\mathrm{b}}$ \\
Diabetic + POH (100mg/kg b w) & $0.26 \pm 0.02^{\mathrm{b}^{*}}$ & $1.79 \pm 0.14^{\mathrm{b}^{*}}$ & $2.05 \pm 0.16^{\mathrm{b}^{*}}$ & $0.34 \pm 0.03^{\mathrm{b}^{*}}$ \\
Diabetic + Glibenclamide (6mg/kg b w) & $0.23 \pm 0.02^{\mathrm{b}^{*}}$ & $1.56 \pm 0.12^{\mathrm{b}^{*}}$ & $1.59 \pm 0.13^{\mathrm{b}^{*}}$ & $0.28 \pm 0.02^{\mathrm{b}^{*}}$ \\
\hline
\end{tabular}

TBARS in plasma and tissues were expressed as $\mu$ moles/dl plasma and $\mu$ moles/g tissue. All values are expressed as mean \pm SD for six rats in each group. One-way ANOVA followed by Duncan's multiple range test (DMRT). Statistical significance was compared within the groups as follows: ${ }^{a}$ control rats; ${ }^{b}$ diabetic control rats. Values are statistically significant at ${ }^{*} p<0.05$. 
Table 3: Effect of Perillyl alcohol on Lipid peroxidation by product (LOOH) in plasma and different organs on High fat diet- low dose Streptozotocin induced diabetic rats.

\begin{tabular}{lcccc}
\multicolumn{1}{c}{ Groups } & Plasma & Liver & Kidney & Pancreas \\
\hline Normal control & $10.01 \pm 0.74$ & $75.10 \pm 5.74$ & $66.87 \pm 5.10$ & $17.52 \pm 1.17$ \\
Diabetic (HFD+STZ) & $18.67 \pm 1.44^{\mathrm{a}^{*}}$ & $124.02 \pm 9.26^{\mathrm{a}^{*}}$ & $167.16 \pm 12.49^{\mathrm{a}^{*}}$ & $29.39 \pm 2.25^{\mathrm{a}^{*}}$ \\
Diabetic + POH (50mg/kg b w) & $14.36 \pm 0.86^{\mathrm{b}^{*}}$ & $101.09 \pm 4.77^{\mathrm{b}^{*}}$ & $120.55 \pm 7.14^{\mathrm{b}^{*}}$ & $23.56 \pm 1.35^{\mathrm{b}^{*}}$ \\
Diabetic + POH (100mg/kg b w) & $13.03 \pm 0.92^{\mathrm{b}^{*}}$ & $87.79 \pm 5.61^{\mathrm{b}^{*}}$ & $82.77 \pm 6.14^{\mathrm{b}^{*}}$ & $20.68 \pm 1.51^{\mathrm{b}^{*}}$ \\
Diabetic + Glibenclamide (6mg/kg b w) & $11.89 \pm 0.83^{\mathrm{b}^{*}}$ & $78.30 \pm 5.92^{\mathrm{b}^{*}}$ & $73.10 \pm 5.44^{\mathrm{b}^{*}}$ & $18.89 \pm 1.37^{\mathrm{b}^{*}}$ \\
\hline
\end{tabular}

LOOH in plasma and tissues were expressed as $\mathrm{x} 10^{-5} \mathrm{mmoles} / \mathrm{dl}$ plasma and mmoles $/ \mathrm{g}$ tissue. All values are expressed as mean \pm SD for six rats in each group. One-way ANOVA followed by Duncan's multiple range test (DMRT). Statistical significance was compared within the groups as follows: ${ }^{\text {ac }}$ control rats; ${ }^{b}$ diabetic control rats. Values are statistically significant at ${ }^{*} p<0.05$. LOOH: lipid hydroperoxides.

Table 4: Effect of Perillyl alcohol on enzymatic antioxidant SOD in plasma and different organs on High fat diet- low dose Streptozotocin induced diabetic rats.

\begin{tabular}{lcccc}
\hline \multicolumn{1}{c}{ Groups } & Plasma & Liver & Kidney & Pancreas \\
\hline Normal control & $7.30 \pm 0.65$ & $10.02 \pm 0.73$ & $14.52 \pm 1.21$ & $3.20 \pm 0.24$ \\
Diabetic (HFD+STZ) & $4.29 \pm 0.42^{\mathrm{a}^{*}}$ & $4.58 \pm 0.34^{\mathrm{a}^{*}}$ & $6.76 \pm 0.62^{\mathrm{a}^{*}}$ & $1.70 \pm 0.12^{\mathrm{a}^{*}}$ \\
Diabetic + POH (50mg/kg b w) & $5.02 \pm 0.36^{\mathrm{b}^{*}}$ & $6.60 \pm 0.56^{\mathrm{b}^{*}}$ & $10.66 \pm 0.72^{\mathrm{b}^{*}}$ & $2.11 \pm 0.20^{\mathrm{b}^{*}}$ \\
Diabetic + POH (100mg/kg b w) & $6.02 \pm 0.32^{\mathrm{b}^{*}}$ & $8.03 \pm 0.55^{\mathrm{b}^{*}}$ & $12.44 \pm 0.82^{\mathrm{b}^{*}}$ & $2.53 \pm 0.19^{\mathrm{b}^{*}}$ \\
Diabetic + Glibenclamide (6mg/kg b w) & $7.01 \pm 0.54^{\mathrm{b}^{*}}$ & $9.69 \pm 0.68^{\mathrm{b}^{*}}$ & $13.54 \pm 1.23^{\mathrm{b}^{*}}$ & $2.90 \pm 0.21^{\mathrm{b}^{*}}$ \\
\hline
\end{tabular}

SOD for tissues were expressed as $50 \%$ inhibition of nitroblue tetrazolium reduced in 1 minute/mg protein. All values are expressed as mean \pm SD for six rats in each group. One-way ANOVA followed by Duncan's multiple range test (DMRT). Statistical significance was compared within the groups as follows: ${ }^{\mathrm{a}}$ control rats; ${ }^{\mathrm{b}}$ diabetic control rats. Values are statistically significant at ${ }^{*} p<0.05$.

Table 5: Effect of Perillyl alcohol on enzymatic antioxidant CAT in plasma and different organs on High fat diet- low dose Streptozotocin induced diabetic rats.

\begin{tabular}{lcccc}
\hline \multicolumn{1}{c}{ Groups } & Plasma & Liver & Kidney & Pancreas \\
\hline Normal control & $176.37 \pm 13.35$ & $82.03 \pm 6.17$ & $41.27 \pm 3.07$ & $0.73 \pm 0.05$ \\
Diabetic (HFD+STZ) & $104.21 \pm 7.90^{\mathrm{a}^{*}}$ & $53.69 \pm 4.03^{\mathrm{a}^{*}}$ & $20.29 \pm 1.48^{\mathrm{a}^{*}}$ & $0.37 \pm 0.03^{\mathrm{a}^{*}}$ \\
Diabetic + POH (50mg/kg b w) & $140.21 \pm 9.32^{\mathrm{b}^{*}}$ & $56.63 \pm 4.65^{\mathrm{b}^{*}}$ & $25.56 \pm 2.53^{\mathrm{b}^{*}}$ & $0.58 \pm 0.06^{\mathrm{b}^{*}}$ \\
Diabetic + POH (100mg/kg b w) & $162.35 \pm 13.29^{\mathrm{b}^{*}}$ & $69.73 \pm 5.23^{\mathrm{b}^{*}}$ & $33.57 \pm 2.40^{\mathrm{b}^{*}}$ & $0.63 \pm 0.05^{\mathrm{b}^{*}}$ \\
Diabetic + Glibenclamide (6mg/kg b w) & $168.95 \pm 12.86^{\mathrm{b}^{*}}$ & $76.30 \pm 5.69^{\mathrm{b}^{*}}$ & $39.04 \pm 2.91^{\mathrm{b}^{*}}$ & $0.69 \pm 0.05^{\mathrm{b}^{*}}$ \\
\hline
\end{tabular}

CAT for tissues were expressed as $\mu$ moles of $\mathrm{H}_{2} \mathrm{O}_{2}$ consumed/minute/mg protein. All values are expressed as mean $\pm \mathrm{SD}$ for six rats in each group. One-way ANOVA followed by Duncan's multiple range test (DMRT) . Statistical significance was compared within the groups as follows: ${ }^{a}$ control rats; ${ }^{b}$ diabetic control rats. Values are statistically significant at ${ }^{*} p<0.05$. CAT- catalase.

Table 6: Effect of Perillyl alcohol on enzymatic antioxidant GPx in plasma and different organs on High fat diet- low dose Streptozotocin induced diabetic rats.

\begin{tabular}{lcccc}
\hline \multicolumn{1}{c}{ Groups } & Plasma & Liver & Kidney & Pancreas \\
\hline Normal control & $16.17 \pm 1.16$ & $12.01 \pm 0.84$ & $8.42 \pm 0.63$ & $1.72 \pm 0.12$ \\
Diabetic (HFD+STZ) & $6.09 \pm 0.54^{\mathrm{a}^{*}}$ & $4.28 \pm 0.37^{\mathrm{a}^{*}}$ & $4.12 \pm 0.31^{\mathrm{a}^{*}}$ & $0.83 \pm 0.07^{\mathrm{a}^{*}}$ \\
Diabetic + POH (50mg/kg b w) & $11.02 \pm 0.78^{\mathrm{b}^{*}}$ & $7.35 \pm 0.60^{\mathrm{b}^{*}}$ & $5.24 \pm 0.12^{\mathrm{b}^{*}}$ & $1.02 \pm 0.12^{\mathrm{b}^{*}}$ \\
Diabetic + POH (100mg/kg b w) & $13.21 \pm 0.99^{\mathrm{b}^{*}}$ & $9.50 \pm 0.72^{\mathrm{b}^{*}}$ & $6.38 \pm 0.48^{\mathrm{b}^{*}}$ & $1.40 \pm 0.10^{\mathrm{b}^{*}}$ \\
Diabetic + Glibenclamide (6mg/kg b w) & $14.23 \pm 1.07^{\mathrm{b}^{*}}$ & $10.40 \pm 0.79^{\mathrm{b}^{*}}$ & $7.50 \pm 0.58^{\mathrm{b}^{*}}$ & $1.58 \pm 0.11^{\mathrm{b}^{*}}$ \\
\hline
\end{tabular}

GPx for tissues were expressed as $\mu \mathrm{g}$ of GSH consumed /minute/mg protein. All values are expressed as mean \pm SD for six rats in each group. One-way ANOVA followed by Duncan's multiple range test (DMRT). Statistical significance was compared within the groups as follows: ${ }^{\mathrm{a}} \mathrm{Control}$ rats; ${ }^{\mathrm{b}}$ diabetic control rats. Values are statistically significant at ${ }^{*} p<0.05$.

\section{Effect of $\mathrm{POH}$ on non-enzymatic antioxidants}

Tables 7-9 shows the level of non-enzymatic antioxidants in plasma and other body tissues (liver, kidney and pancreas) of control and diabetic rats. The GSH, vitamin C and Vitamin-E levels were significantly declined due to the increase in oxidative stress in diabetic control rats when compared to normal rats. These abnormal levels of non-enzymatic antioxidants GSH, vitamin-C and Vitamin-E significantly elevated near to normal levels in $\mathrm{POH}$ treated diabetic rats for the period of 30 days.

\section{DISCUSSIONS}

Metabolic disturbances and Insulin Resistance caused by obesity have been linked to Oxidative Stress. Both in humans with obesity and in animals which are used for experiments, obesity has been linked with the increase in Oxidative Stress markers. ${ }^{24-26}$ An increase in Oxidative Stress in the body if fixed with an attenuated antioxidant capacity of the body tends to disrupt the normal redox homeostasis leading to irreversible damage to the cell membranes and other macromolecules inside the body. ${ }^{27,28}$ High Fat Diet administration is now-a-days 
Table 7: Effect of Perillyl alcohol on non-enzymatic antioxidant GSH in plasma and different organs on High fat diet- low dose Streptozotocin induced diabetic rats.

\begin{tabular}{lcccc}
\hline \multicolumn{1}{c}{ Groups } & Plasma & Liver & Kidney & Pancreas \\
\hline Normal control & $31.09 \pm 2.29$ & $14.06 \pm 0.99$ & $12.81 \pm 0.95$ & $1.82 \pm 0.13$ \\
Diabetic (HFD+STZ) & $14.23 \pm 1.17^{\mathrm{a}^{*}}$ & $8.12 \pm 0.61^{\mathrm{a}^{*}}$ & $6.75 \pm 0.51^{\mathrm{a}^{*}}$ & $0.96 \pm 0.07^{\mathrm{a}^{*}}$ \\
Diabetic + POH (50mg/kg b w) & $19.12 \pm 1.23^{\mathrm{b}^{*}}$ & $9.56 \pm 0.87^{\mathrm{b}^{*}}$ & $9.65 \pm 0.69^{\mathrm{b}^{*}}$ & $1.02 \pm 0.12^{\mathrm{b}^{*}}$ \\
Diabetic + POH (100mg/kg b w) & $24.17 \pm 1.76^{\mathrm{b}^{*}}$ & $11.66 \pm 0.88^{\mathrm{b}^{*}}$ & $10.67 \pm 0.80^{\mathrm{b}^{*}}$ & $1.48 \pm 0.11^{\mathrm{b}^{*}}$ \\
Diabetic + Glibenclamide (6mg/kg b w) & $27.02 \pm 1.99^{\mathrm{b}^{*}}$ & $12.47 \pm 0.95^{\mathrm{b}^{*}}$ & $11.49 \pm 0.87^{\mathrm{b}^{*}}$ & $1.68 \pm 0.12^{\mathrm{b}^{*}}$ \\
\hline
\end{tabular}

GSH for plasma and tissues were expressed as $\mathrm{mg} / \mathrm{dl}$ and $\mu \mathrm{g} / \mathrm{mg}$ protein. All values are expressed as mean \pm SD for six rats in each group. One-way ANOVA followed by Duncan's multiple range test (DMRT). Statistical

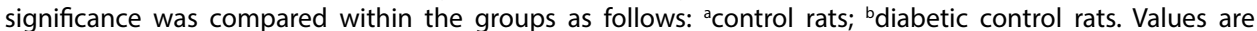
statistically significant at ${ }^{*} p<0.05$.

Table 8: Effect of Perillyl alcohol on non-enzymatic antioxidant Vitamin C in plasma and different organs on High fat diet- low dose Streptozotocin induced diabetic rats.

\begin{tabular}{lllll}
\multicolumn{1}{c}{ Groups } & \multicolumn{1}{c}{ Plasma } & \multicolumn{1}{c}{ Liver } & \multicolumn{1}{c}{ Kidney } & \multicolumn{1}{c}{ Pancreas } \\
\hline Normal control & $2.22 \pm 0.15$ & $0.87 \pm 0.07$ & $0.77 \pm 0.06$ & $2.51 \pm 0.18$ \\
Diabetic (HFD+STZ) & $0.66 \pm 0.06^{\mathrm{a}^{*}}$ & $0.42 \pm 0.03^{\mathrm{a}^{*}}$ & $0.47 \pm 0.04^{\mathrm{a}^{*}}$ & $1.42 \pm 0.10^{\mathrm{a}^{*}}$ \\
Diabetic + POH (50mg/kg b w) & $1.03 \pm 0.14^{\mathrm{b}^{*}}$ & $0.58 \pm 0.06^{\mathrm{b}^{*}}$ & $0.60 \pm 0.06^{\mathrm{b}^{*}}$ & $1.88 \pm 0.12^{\mathrm{b}^{*}}$ \\
Diabetic + POH (100mg/kg b w) & $1.58 \pm 0.13^{\mathrm{b}^{*}}$ & $0.70 \pm 0.05^{\mathrm{b}^{*}}$ & $0.66 \pm 0.05^{\mathrm{b}^{*}}$ & $2.29 \pm 0.16^{\mathrm{b}^{*}}$ \\
Diabetic + Glibenclamide (6mg/kg b w) & $1.85 \pm 0.14^{\mathrm{b}^{*}}$ & $0.81 \pm 0.08^{\mathrm{b}^{*}}$ & $0.73 \pm 0.06^{\mathrm{b}^{*}}$ & $2.40 \pm 0.18^{\mathrm{b}^{*}}$ \\
\hline
\end{tabular}

Vitamin C for plasma and tissues were expressed as $\mathrm{mg} / \mathrm{dl}$ and $\mu \mathrm{mole} / \mathrm{mg}$ tissue respectively. All values are expressed as mean \pm SD for six rats in each group. One-way ANOVA followed by Duncan's multiple range test (DMRT). Statistical significance was compared within the groups as follows: ${ }^{\mathrm{a}}$ control rats; ${ }^{\mathrm{b}}$ diabetic control rats. Values are statistically significant at ${ }^{*} p<0.05$.

Table 9: Effect of Perillyl alcohol on non-enzymatic antioxidant Vitamin E in plasma and different organs on High fat diet- low dose Streptozotocin induced diabetic rats.

\begin{tabular}{lcccc}
\hline \multicolumn{1}{c}{ Groups } & Plasma & Liver & Kidney & Pancreas \\
\hline Normal control & $1.92 \pm 0.14$ & $5.75 \pm 0.44$ & $3.62 \pm 0.27$ & $2.65 \pm 0.20$ \\
Diabetic (HFD+STZ) & $1.11 \pm 0.23^{\mathrm{a}^{*}}$ & $2.65 \pm 0.28^{\mathrm{a}^{*}}$ & $1.27 \pm 0.10^{\mathrm{a}^{*}}$ & $1.36 \pm 0.10^{\mathrm{a}^{*}}$ \\
Diabetic + POH (50mg/kg b w) & $1.70 \pm 0.15^{\mathrm{b}^{*}}$ & $3.56 \pm 0.36^{\mathrm{b}^{*}}$ & $2.02 \pm 0.33^{\mathrm{b}^{*}}$ & $2.01 \pm 0.16^{\mathrm{b}^{*}}$ \\
Diabetic + POH (100mg/kg b w) & $1.75 \pm 0.17^{\mathrm{b}^{*}}$ & $4.66 \pm 0.35^{\mathrm{b}^{*}}$ & $2.92 \pm 0.22^{\mathrm{b}^{*}}$ & $2.33 \pm 0.18^{\mathrm{b}^{*}}$ \\
Diabetic + Glibenclamide (6mg/kg b w) & $1.81 \pm 0.17^{\mathrm{b}^{*}}$ & $4.85 \pm 0.38^{\mathrm{b}^{*}}$ & $3.42 \pm 0.32^{\mathrm{b}^{*}}$ & $2.56 \pm 0.20^{\mathrm{b}^{*}}$ \\
\hline
\end{tabular}

Vitamin E for plasma and tissues were expressed as $\mathrm{mg} / \mathrm{dl}$ and $\mu \mathrm{mole} / \mathrm{mg}$ tissue respectively. All values are expressed as mean \pm SD for six rats in each group. One-way ANOVA followed by Duncan's multiple range test (DMRT). Statistical significance was compared within the groups as follows: ${ }^{\mathrm{a}}$ control rats; ${ }^{\text {b }}$ diabetic control rats. Values are statistically significant at ${ }^{*} p<0.05$

routinely employed in the experimental models mostly rats or mice for obesity and metabolic syndrome to display an increase in weight, IR, and dyslipidemic changes. It has been argued that excessive accumulation of fat by giving HFD to animal models leads to enhanced production of ROS in adipocytes and systemic tissues. Obesity, IR and hyperglycemia, develop over a period of several weeks of High Fat Diet administration and it has been demonstrated that increased OS precedes these changes. ${ }^{29}$ Addressing these elevated levels of stress is therefore likely to afford protection against or amelioration of the metabolic consequences caused by HFD. In the present study, rats were fed with HFD for 4 weeks followed by Low dose STZ injection. Two treatment groups, Perillyl alcohol either at $50 \mathrm{mg}$ and $100 \mathrm{mg} / \mathrm{kg}$ body weight per day, were administered for 30 days. At the end of experiment, markers of OS, antioxidant defense, were investigated. A group of rats on standard diet (ND) for the same period served as the Normal control while another group on HFD-Low Dose STZ (35 mg/kg b.w) (without Perillyl alcohol) served as the Diabetic control.

DM has been reported to produce ROS that surpasses the local antioxidant capacity of the system. Free radicals like hydroxyl radicals $\left({ }^{\circ} \mathrm{OH}\right)$, superoxide anion $\left(\mathrm{O}^{\circ}-\right)$, lipid peroxyl radicals $\left(\mathrm{LOO}^{\circ}\right)$, peroxyl radicals $\left(\mathrm{ROO}^{\circ}\right)$ and hydrogen peroxide $\left(\mathrm{H}_{2} \mathrm{O}_{2}\right)$ are mainly produced during the developing stages of diabetes. These free radicals produced may react with the polyunsaturated fatty acids of the cell membranes, which lead to lipid peroxidation. ${ }^{30}$ This in turn, leads to extensive damage to the cell membranes which causes impairment of membrane functions due to a decrease in membrane fluidity. ${ }^{31}$ In our work, we observed in rats treated with HFD-Low dose STZ that there was a significant increase in the levels of TBARS and LOOH in the plasma and other tissues of diabetic rats. The increased levels of TBARS and $\mathrm{LOOH}$ contents in the diabetic rats imply that peroxidative injury may be associated with the development of diabetic complications. Treatment with $\mathrm{POH}$ (50 and $100 \mathrm{mg} / \mathrm{kg}$ b.w) and Glibenclamide reduced the levels of TBARS and $\mathrm{LOOH}$ in plasma and other tissues when compared with the diabetic rats suggests that $\mathrm{POH}$ has the potential to scavenge free radicals. In all the organisms, antioxidant enzymes form the main line of defence against the ROS generated. These enzymes include SOD, CAT as well as GPx. In diabetes, disturbances in the antioxidant defences system and reactive oxygen species (ROS) induced oxidative damage in the pathogenesis of DM associated disorders have also been previously reported by ${ }^{32}$ Therefore, treatment with phytochemicals may contribute to the prevention as well as the postponement of diabetic associated complications. ${ }^{33}$ However, the interactions between the oral hypoglycemic drugs and the phytochemical in terms of stability, bioavailability, and metabolism have to be established for successful therapeutic strategies. ${ }^{34}$ High Fat Diet induced Oxidative stress is engaged in the development of diabetes and also its later complications are well mimicked by the diabetogenic action of STZ administration and also lead to chronic hyperglycemia. 
SOD the enzymatic antioxidant provides protection to tissues against ROS by catalyzing the removal of superoxide radicals, converting them into $\mathrm{H}_{2} \mathrm{O}_{2}$ and molecular oxygen which damage the cell membranes and other biological structures, in the body. The observed decrease in SOD activity could result from inactivation by $\mathrm{H}_{2} \mathrm{O}_{2}$ or by glycation of enzymes. ${ }^{35}$ In $\mathrm{POH}$ treated diabetic rats, showed improved levels of SOD compared diabetic control rat. From this result, $\mathrm{POH}$ may be inhibited the reactive oxygen-free radicals and also enhanced the tissue antioxidant enzymes activity.

CAT is a heme protein which helps to catalyzes the reduction of hydrogen peroxides and protects the tissues of body from the highly reactive hydroxyl radicals. A decrease in CAT activity in diabetic rats may be a result of inactivation of the enzyme by glycation. ${ }^{36}$ CAT reduces hydrogen peroxide that is produced by a dismutation reaction. CAT also prevents the body from the generation of hydroxyl radicals, thereby protecting the cellular constituents from oxidative damage in peroxisomes. The reduced activity of CAT in HFD-STZ treated rats might result from the accumulation of $\mathrm{H}_{2} \mathrm{O}_{2}$, which produces deadly effects. In this investigation, CAT levels were significantly increased in plasma and other tissues like Pancreas, kidney, liver of $\mathrm{POH}$ treated rats, may be $\mathrm{POH}$ prohibited hydroxyl radicals and its antioxidant nature.

Glutathione peroxidase (GPx), a selenium-containing enzyme present in significant concentrations in the body, detoxifies $\mathrm{H}_{2} \mathrm{O}_{2}$ to $\mathrm{H}_{2} \mathrm{O}$ through the oxidation of reduced GSH. Reduced activity of GPx may result from radical-induced inactivation and glycation of the enzyme..$^{37}$ The lowered GPx activity could be directly explained by the low content of GSH which is substrate and cofactor of GPx found in the diabetic state. Reduced activity of GPx in the tissues was observed during diabetes condition, which may lead to a number of harmful effects because of the accumulation of toxic products. Other study from researchers also reported a decrease in the activity of GPx in the tissues of diabetic rats. ${ }^{38}$ In $\mathrm{POH}$ treated $50 \mathrm{mg}$ and $100 \mathrm{mg} / \mathrm{kg}$ body weight diabetic rats, the levels of GPx were elevated in plasma and tissues. Therefore, $\mathrm{POH}$ a monoterpene possesses the ability to inhibit the levels of $\mathrm{H}_{2} \mathrm{O}_{2}$ by its anti-peroxidative activity.

The non-enzymic antioxidant Glutathione is a tripeptide, present intracellular helps in protection of cellular systems from the adverse effects of lipid peroxidation. GSH directly scavenges free radicals formed during Lipid peroxidation and acts as a co-substrate for peroxide detoxification by glutathione peroxidases. ${ }^{38}$ When the oxidative stress increases in the body due to a significant increase in aldehydic products or free radials of lipid peroxidation could probably decrease GSH availability in the cell. ${ }^{39}$ Moreover, treatment with $\mathrm{POH}$ $50 \mathrm{mg}$ and $100 \mathrm{mg} / \mathrm{kg}$ resulted in the elevation of the GSH levels, in the diabetic treated rats which protects the cell membrane from the oxidative damage by regulating the redox status. ${ }^{40}$ Vitamin $\mathrm{C}$ plays an important role in the antioxidant system of body which protects all lipids from undergoing oxidation. Also, it helps in withdrawing count of apoptotic cells ${ }^{41}$ and helps to regenerate vitamin $\mathrm{E}$ from its oxidized state. $^{42}$ On the other hand, Vitamin $\mathrm{E}$ is a non-enzymatic antioxidant, which also helps in reducing chain reactions associated with lipid peroxidation. ${ }^{43}$ Vitamin $\mathrm{E}$ is very important antioxidant because it is reported to be very effective in the glycemic control and also helps in lowering the level of $\mathrm{HbAlc}$, the glycated haemoglobin used as a marker to measure average blood glucose of three months. ${ }^{44}$ Several evidences and researches indicate that the reductions in the levels of non-enzymatic antioxidants are associated with HFD-STZ induced diabetic rats. ${ }^{45,46}$ In our studies, Perillyl alcohol administration in High Fat Diet and STZ induced experimental DM rats express near normal levels of GSH, vitamin C and E display the potential of Perillyl alcohol to restore the antioxidant reserves.

\section{CONCLUSION}

In conclusion, this study has demonstrated that the effect of Perillyl alcohol a monoterpene reduces the oxidative stress when administrated orally for the period of 30 days in HFD-Low Dose STZ-induced diabetic rats by decreasing lipid peroxidation and sparing the activities of antioxidant enzymes. Therefore, Perillyl alcohol can be considered as a safe food supplement with a potential as an antidiabetic agent in diabetic complications. Thus, in the near future, Perillyl alcohol may play a very important role in modern system of medicine.

\section{AKNOWLEDGEMENT}

The authors would like to express their thanks to the Department of Zoology (UGC-SAP Sponsored), Annamalai University for providing the infrastructure facility and support.

\section{CONFILICTS OF INTEREST}

The authors declare that there is no conflict of interest.

\section{FUNDING SOURCE}

Nil.

\section{ABBREVIATIONS}

POH: Perillyl alcohol; LPO: Lipid peroxidation; STZ: Streptozotocin; HFD: High Fat Diet; ND: Normal Diet; SOD: Superoxide dismutase; CAT: Catalase; GPx: Glutathione peroxidase; TBARS: thiobarbituric acid reactive substances; LOOH: lipid hydroperoxides; ROS: Reactive oxygen species; MDA: malondialdehyde.

\section{REFERENCES}

1. Rosen P, Nawroth PP, King G, Moller W, Tritschler HJ, Packer L. The role of oxidative stress in the onset and progression of diabetes and its complications: A summary of a Congress Series sponsored by UNESCO-MCBN, the American Diabetes Association and the German Diabetes Society. Diabetes Metab Res Rev. 2001;17:189-212.

2. Finamor IA, EM Saccol, D Gabriel, GM Ourique, AP Riffel, SP Konrad, et al. Effects of parboiled rice diet on oxidative stress parameters in kidney of rats with streptozotocin-induced diabetes. J Med Food. 2012;15:598-604.

3. Memisogulları R, Bakan E. Levels of ceruloplasmin, transferrin, and lipid peroxidation in the serum of patients with type 2 diabetes mellitus. J Diabetes Complications. 2004;18:193-7.

4. Bonnefont-Rousselot D, Bastard JP, Jaudon MC, Delattre J. Consequences of the diabetic status on the oxidant/antioxidant balance. Diabetes Metab. 2000;26:163-76

5. Robertson RP, Harmon J, Tran PO, Tanaka Y, Takanashi H. Glucose toxicity in beta-cell: type 2 diabetes, good radicals gone bad, and the glutathione connection. Diabetes. 2003;52:581-7.

6. Rajasekaran S, Sivagnanam K, Subramanian S. Antioxidant effect of Aloe vera gel extract in streptozotocin-induced diabetes in rats. Pharmacol Rep. 2005;57:90-6.

7. Duzguner V, Kucukgul A, Erdogan S, Celik S, Sahin K. Effect of lycopene administration on plasma glucose, oxidative stress and body weight in streptozotocin diabetic rats. J Appl Anim Res. 2008;33:17-20.

8. Arafat M, Salam A, Arafat O. The association of Type 2 diabetes with obesity and other factors: In multinational community. Int J Pharm Pharm Sci. 2014;6:25760.

9. Gupta RK, Kesari AN, Murthy PS, Chandra R, Tandon V, Watal G. Hypoglycemic and antidiabetic effect of ethanolic extract of leaves of Annona squamosa $L$. in experimental animals. J Ethnopharmacol. 2005;99:75-81.

10. Belanger J.T. Perillyl alcohol: applications in oncology. Altern Med Rev. 1998;3(6):448-57

11. Ansari MA, Z Fatima, S Hameed. Anticandidal effect and mechanisms of monoterpenoid, perillyl alcohol against Candida albicans. PLoS. 2016;11(9)2307.

12. Bailey HH, S Attia, RR Love, T Fass, R Chappell, K Tutsch, et al. Phase II trial of daily oral perillyl alcohol (NSC 641066) in treatment-refractory metastatic breast cancer. Cancer Chemother Pharmacol. 2008;62(1):149-57. 
13. Magdalena Jeszka-Skowron, Ewa Flaczyk, Jan Jeszka, Zbigniew Krejpcio, Ewelina Król, Maciej S. Mulberry leaf extract intake reduces hyperglycaemia in streptozotocin (STZ)-induced diabetic rats fed high-fat diet. Journal of Functional Foods. 2014;8:9-17.

14. Trinder P. Determination of glucose in blood using glucose oxidase with an alternative oxygen acceptor. Ann Clin Biochem. 1969;6:24-30.

15. Berg JM, Tymoczko JL, Stryer L. Glycolysis and glyconeogensis. In: Berg JM, Tymoczko JL, Stryer L (eds). Biochemistry. WH Freeman and Company, New York. 2001;425-64.

16. Niehaus WG, Samuelsson JRB. Formation of malonaldehyde from phospholipid arachidonate during microsomal lipid peroxidation. Eur J Biochem. 1968;6:126-30.

17. Jiang ZY, Hunt JV, Wolff SP. Ferrous ion oxidation in the presence of xylenol orange for detection of lipid hydroperoxides in low density lipoprotein. Anal Biochem. 1992;202:384-9.

18. Kakkar P, Das B, Viswanathan PN. A modified spectrophotometric assay of SOD. Indian J Biochem Biophys. 1984;21:130-2.

19. Sinha KA. Colorimetric assay of catalase. Anal Biochem. 1972;47:389-94.

20. Rotruck JT, Pope AL, Ganther HE, Swanson AB, Hafeman DG, Hoekstra WG. Selenium: biochemical roles as a component of glutathione peroxidase. Science. 1973;179:588-90.

21. Ellman GL. Tissue sulphydryl. Arch Biochem Biophys. 1959;82:70-7.

22. Roe JH, Kuether CA. The determination of ascorbic acid in whole blood and urine through the 2,4 dinitrophenylhydrazine derivative of dehydroascorbic acid. J Biol Chem. 1943;11:145-64.

23. Baker H, Frankel O, DeAngelis B, Feingold S. Plasma tocopherol in man at various times after ingestion of free or acetylated tocopherol. Nutr Res. 1980;21:531-6.

24. Urakawa $\mathrm{CH}$, Katsuki CA, Sumida CY, Gabazza CE, Murashima CS, Morioka $\mathrm{CK}$, et al. Oxidative stress is associated with adiposity and insulin resistance in men. J Clin Endocrinol Metab. 2003;88(10):4673-6.

25. Furukawa $S$, Fujita $T$, Shimabukuro $M$, Iwaki $M$, Yamada $Y$, Nakajima $Y$, et al. Increased oxidative stress in obesity and its impact on metabolic syn-drome. J Clin Invest. 2004;114(12):1752-61.

26. Diniz YS, Rocha KKHR, Souza GA, Novelli ELB, Galhardi CM, Ebaid GMX, et al. Effects of $\mathrm{N}$-acetylcysteine on sucrose-rich diet-induced hyperglycaemia, dyslipidemia and oxidative stress in rats (Report). Eur J Pharmacol 2006 543(13):151-62

27. Kamata $H$, Hirata $H$. Redox regulation of cellular signalling. Cell Signal. 1999;11(1):1-14.

28. Levine RL, Stadtman ER. Oxidative modification of proteins during aging. Exp Gerontol. 2001;36(9):1495-503.

29. Matsuzawa-Nagata N, Takamura T, Ando H, Nakamura S, Kurita S, Misu H, et al. Increased oxidative stress precedes the onset of high-fat diet-induced insulin resistance and obesity (Report). Metabolism 2008;57(8):1071-7.

30. Lery V, Zaltzber H, Ben-Amotz A, Kanter Y, Aviram M. b-Carotene affects antioxidant status in non-insulin dependent diabetes mellitus. Pathophysiology. 1999;6:157-62.
31. Alfy A, Ahmed A, Fatani A. Protective effect of red grape seeds proanthocyanidins against induction of diabetes by alloxan in rats. Pharmacol Res. 2005;52:264 70.

32. Maritim AC, Sanders RA, Watkins JB. Diabetes, oxidative stress and antioxidants. J Biochem Mol Toxicol. 2003;17(1):24-38.

33. Suryanarayana P, Saraswat M, Mrudula T, Krishna TP, Krishnaswamy K, Reddy GB. Curcumin and turmeric delay streptozotocin-induced diabetic cataract in rats. Invest Ophthalmol Vis Sci. 2005;46(6):2092-9.

34. Panchal I, Sen DJ, Navle A, Shah U. Structure-based drug designing, scoring, and synthesis of some substituted sulphonylureas/guanidine- based derivatives as hypoglycemic agents. Int J Pharm Pharm Sci. 2017;9:226-32.

35. Sozmen BY, Sozmen B, Delen Y, Onat T. Catalase/superoxidedismutase (SOD) and catalase/paraoxonase (PON) ratios may implicate poor glycemic control Arch Med Res. 2001;32:283-7.

36. Yan $\mathrm{H}$, Harding JJ. Glycation-induced inactivation and loss of antigenicity of catalase and superoxide dismutase. Biochem J. 1997;328:599-604.

37. Winterbourn CC. Concerted antioxidant activity of glutathione and superoxide dismutase. In: Packer, L., Fuchs, J. (Eds.), Biothiols in Health and Disease. Marcel Dekker Inc., New York 1995;117-34.

38. AliciguzelY, Ozen I, Aslan M, Karayalcin U. Activities of xanthine oxidoreductase and antioxidant enzymes in different tissues of diabetic rats. J Lab Clin Med. 2003;142(3):172-7.

39. Mohammed $\mathrm{AH}$, Antidiabetic and antioxidant activity of Jasonia montana extract in streptozotocin-induced diabetic rats. Saudi Pharmaceutical Journal. 2008; 16:3-4.

40. Inove M, Saito $Y$, Hirato E, Morino $Y$, Nagase $S$. Regulation of redox status of plasma proteins by mechanism and transport of glutathione and related compounds. Journal of Protein Chemistry. 1987;36:169-73.

41. Sadi G, Yılmaz O, Güray T. Effect of vitamin C and lipoic acid on streptozotocininduced diabetes gene expression: mRNA and protein expressions of $\mathrm{Cu}-\mathrm{Zn}$ SOD and catalase. Mol. Cell Biochem. 2008;309:109-16.

42. Chen, P.E. Milbury, K. Lapsley, and J.B. Blumberg, Flavonoids from almond skins are bioavailable and act synergistically with vitamins $C$ and $E$ to enhance hamster and human LDL resistance to oxidation. J Nutr. 2005;135:1366-73.

43. VR Punithavathi, R Anuthama, PS Prince. Combined treatment with naringin and vitamin $\mathrm{C}$ ameliorates streptozotocin-induced diabetes in male wistar rats. J Appl Toxicol. 2008;28:806-13.

44. Ihara A, Matsumoto K, Kawamoto T, Shouno S, Kawamoto J, Katayama A, et al. Relationship between hemostatic markers and platelet indices in patients with aortic aneurysm. Pathophysiol Haemost Thromb. 2006;35:451-6.

45. Pavana P, Sethupathy S, Manoharan S. Antihyperglycemic and antilipidperoxidative effects of tephrosia purpurea seed extract in streptozotocin induced diabetic rats. Indian Journal of Clinical Biochemistry. 2007;22(1):77-83.

46. Vishnukumar S, Stephan R. Effect of morin on lipidperoxides and antioxidants in streptozotocin-induced diabetic rats. Int J Pharm Bio. 2012;3(4):770-80.

\section{GRAPHICAL ABSTRACT}

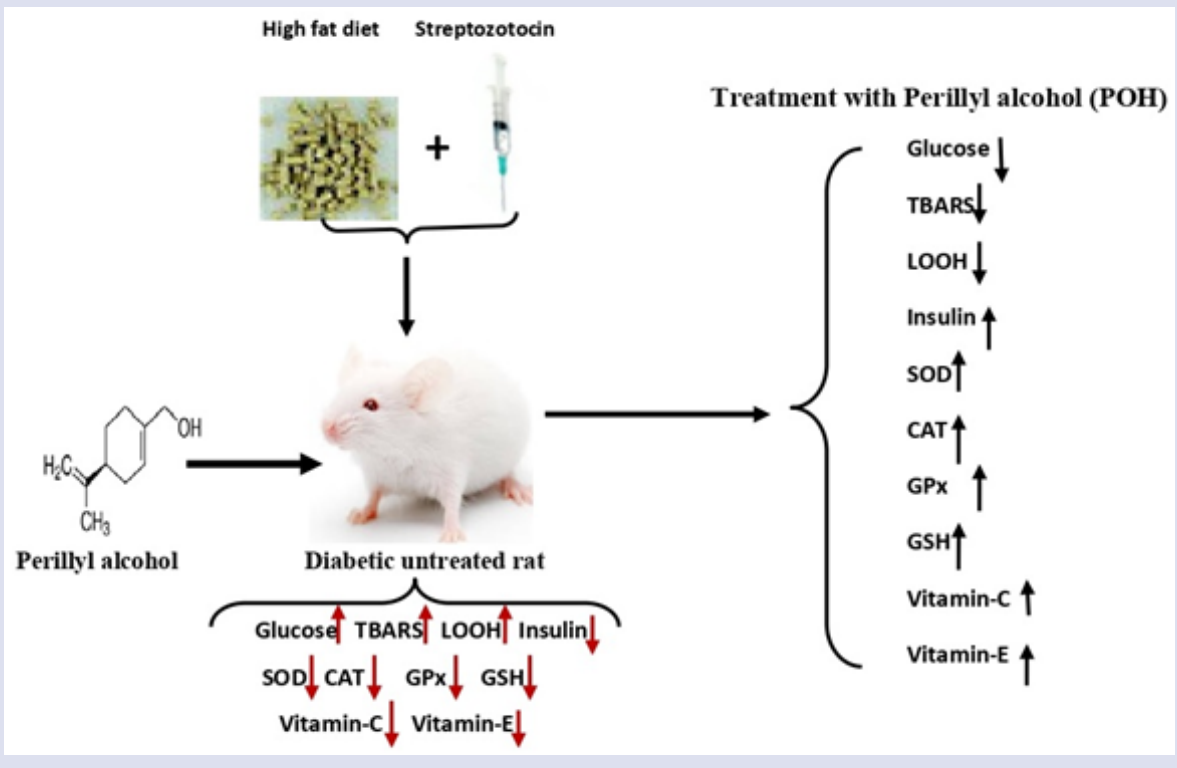




\section{SUMMARY}

- Hyperglycemic effect of Perillyl alcohol (POH) was evaluated in male wistar rats.

- High fat diet-low dose streptozotocin was used to induce experimental diabetes, which caused elevation in blood glucose, Lipid peroxidation markers, enzymatic antioxidants SOD, CAT, GPx and non-enzymatic antioxidants GSH, Vitamin-C and Vitamin-E.

- Perillyl alcohol decreased glucose level and lipid peroxidation and increased antioxidant status significantly.

- Plasma insulin level also decrease in diabetic rats and improved in Perillyl alcohol treated rats.

- These results clearly revealed the antihyperglycemic and antioxidant property of Perillyl alcohol, so it may be more effective at combating diabetic complications.

Cite this article: Hassan T, Elanchezhiyan C, Naseer I, Marimuthu S. Effect of Perillyl Alcohol (POH) A Monoterpene on Lipid Peroxidation and Antioxidant Status in High Fat Diet-Low Dose STZ Induced Type 2 Diabetes in Experimental Rats. Pharmacog J. 2019;11(6)Suppl:1434-41. 